\title{
L-Arginine deficiency causes airway hyperresponsiveness after the late asthmatic reaction
}

\author{
H. Maarsingh, B.E. Bossenga, I.S.T. Bos, H.H. Volders, J. Zaagsma and H. Meurs
}

ABSTRACT: Peroxynitrite has been shown to be crucially involved in airway hyperresponsiveness (AHR) after the late asthmatic reaction (LAR). Peroxynitrite production may result from simultaneous synthesis of nitric oxide (NO) and superoxide by inducible NOsynthase (iNOS) at low L-arginine concentrations. L-Arginine availability to iNOS is regulated by its cellular uptake, which can be inhibited by eosinophil-derived polycations and by arginase, which competes with iNOS for the common substrate.

Using a guinea pig model of allergic asthma, we investigated whether aberrant L-arginine homeostasis could underlie peroxynitrite-mediated AHR after the LAR.

After the LAR, arginase activity in the airways and eosinophil peroxidase release from bronchoalveolar lavage cells were increased. These changes were associated with a 2.0-fold AHR to methacholine as measured in isolated perfused tracheal preparations. AHR was reduced by exogenous L-arginine administration. Moreover, both the arginase inhibitor $\mathbf{N}^{\omega}$-hydroxy-nor-Larginine (nor-NOHA) and the polycation antagonist heparin normalised airway responsiveness. These effects were reversed by the nitric oxide synthase inhibitor $\boldsymbol{N}^{\omega}$-nitro-L-arginine methyl ester (L-NAME), indicating that both agents reduced AHR by restoring bronchodilating NO production.

In conclusion, in allergen-challenged guinea pigs, the AHR after the LAR is caused by arginaseand polycation-induced attenuation of L-arginine availability to iNOS, which may switch the enzyme to simultaneous production of superoxide and NO, and, consequently, peroxynitrite.

KEYWORDS: Allergic asthma, arginase, L-arginine, nitric oxide, peroxynitrite, polycations

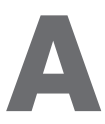
llergic asthma is characterised by airway hyperresponsiveness (AHR) to non-specific stimuli, which may be increased after acute allergic asthmatic reactions. Thus, in allergic asthmatics, as well as in sensitised guinea pigs, increased airway responsiveness to histamine and methacholine develops after both the early asthmatic reaction (EAR) and late asthmatic reaction (LAR) [1, 2].

During the allergen-induced LAR, inducible nitric oxide (NO) synthase (iNOS) is induced in human [3] as well as in guinea pig [4] airways. Significant correlations have been observed in asthmatics between exhaled (iNOS-derived) NO, AHR and airway eosinophilia, which are all reduced after glucocorticosteroid treatment [5-8]. Based on these observations, iNOS-derived NO is considered as a marker of airway inflammation. Importantly, increased levels of exhaled $\mathrm{NO}$ also correlate with increased nitrotyrosine staining (a marker of peroxynitrite) in exhaled breath condensate of mild asthmatics [9]. In addition, increased nitrotyrosine staining of the airway epithelium and inflammatory cells in bronchial biopsies of asthmatic patients correlates with iNOS expression, AHR and airway inflammation [8], whereas glucocorticosteroids decreased the observed nitrotyrosine staining [8,9]. Collectively, these findings indicate that peroxynitrite, the reaction product of $\mathrm{NO}$ and superoxide anion, is importantly involved in iNOS-related asthmatic airway inflammation and hyperresponsiveness.

In an in vivo guinea pig model for allergic asthma, we have previously demonstrated that iNOS may have both beneficial and detrimental effects on allergen-induced AHR to histamine after the LAR, by functional antagonism of the histamineinduced bronchoconstriction and promoting airway inflammation and epithelial damage, respectively [10]. Additionally, in perfused guinea pig airways ex vivo, the AHR after the LAR was reversed by the nonselective nitric oxide synthase (NOS) inhibitor $N^{\omega}$-nitro-L-arginine methyl ester (L-NAME) as well as by the superoxide anion

\section{AFFILIATIONS}

Dept of Molecular Pharmacology, University of Groningen, Groningen, The Netherlands.

\section{CORRESPONDENCE}

H. Maarsingh

Dept of Molecular Pharmacology

University of Groningen

Antonius Deusinglaan 1

9713 AV Groningen

The Netherlands

E-mail: h.maarsingh@rug.nl

Received:

June 112008

Accepted after revision:

Feb 162009

First published online:

Feb 272009 
scavenger superoxide dismutase, indicating that peroxynitrite is strongly involved in the development of AHR after the LAR [11]. It has been well established that formation of peroxynitrite may be effectively induced by simultaneous production of both $\mathrm{NO}$ and superoxide anion by iNOS when the L-arginine substrate availability to the enzyme is low [12]. Increasing the concentration of L-arginine promotes the production of $\mathrm{NO}$, while the generation of superoxide anion, and hence peroxynitrite, is reduced [12].

In line with above mentioned observations, studies have indicated that both under physiological and pathophysiological conditions, $\mathrm{NO}$ production and airway responsiveness are tightly controlled by the availability of L-arginine to NOS [13-15]. L-Arginine is a semi-essential amino acid, which is taken up by the diet and may be endogenously produced from L-citrulline by the intestinal mucosa as well as by some NO-producing cells [15]. L-Arginine requirements in most cells are met via uptake of L-arginine by specific cationic amino acid transporters (CATs) [16]. Thus, the availability of L-arginine for NOS to produce NO in the airways is importantly regulated by cellular transport. Indeed, inhibition of CATs by eosinophil-derived cationic proteins as well as by poly-L-arginine causes decreased NO synthesis in rat alveolar macrophages and tracheal epithelial cells [17], while poly-L-arginine causes AHR to methacholine in perfused guinea pig tracheal tube preparations by inducing a deficiency of constitutive NOS (cNOS)-derived NO in response to this agonist [18].

Substrate availability to NOS is also regulated by arginase, which hydrolyses L-arginine into L-ornithine and urea, and thus competes with NOS for the common substrate [14, 15]. Although classically considered as an enzyme of the urea cycle, arginase is also present in extrahepatic cells and tissues, including various cell types in the airways [14, 19-24]. The functional role of arginase in the airways has been established in isolated guinea pig tracheal preparations. Thus, constitutive arginase activity in these preparations attenuates both agonistinduced, epithelium-derived [20] and inhibitory nonadrenergic noncholinergic nerve-mediated [23] NO production, thereby promoting airway responsiveness to neural and non-neural stimuli.

The role of altered L-arginine homeostasis in the (peroxynitritemediated) development of AHR after the LAR is currently unknown. Therefore, in the present study, we examined the roles of arginase, endogenous polycations and L-arginine availability in the development of AHR after the LAR, using perfused tracheal preparations from ovalbumin-sensitised guinea pigs obtained $24 \mathrm{~h}$ after ovalbumin-challenge. In addition, arginase activity was assessed in tracheal and bronchoalveolar lavage (BAL) cell homogenates, while eosinophil number and release of the polycation eosinophil peroxidase (EPO) were determined in BAL cells.

\section{METHODS}

\section{Animals}

Outbred specified pathogen free guinea pigs (Harlan, Heathfield, UK), weighing 700-900 g, were used in this study. Animals were actively immunoglobulin (Ig)E-sensitised to ovalbumin (Sigma, St. Louis, MO, USA) using aluminium hydroxide (Sigma) as an adjuvant [25] and used experimen- tally 4-8 weeks later. All protocols described in this study were approved by the University of Groningen Committee for Animal Experimentation (University of Groningen, Groningen, The Netherlands).

\section{Allergen provocation}

Ovalbumin challenges were performed as described previously, using a specially designed provocation cage in which the guinea-pigs could move freely [26]. The provocations were performed by inhalation of an aerosol concentration of $0.5 \mathrm{mg} \cdot \mathrm{mL}^{-1}$ ovalbumin in saline and were discontinued when the first signs of respiratory distress were observed. The animals were sacrificed $24 \mathrm{~h}$ after ovalbumin challenge, i.e. after the LAR [2]. Nonchallenged sensitised animals were used as controls.

\section{Tracheal perfusion}

Tracheae were mounted in a perfusion setup as described previously $[20,27,28]$ and placed in an organ bath $\left(37^{\circ} \mathrm{C}\right)$ containing $20 \mathrm{~mL}$ of gassed Krebs-Henseleit medium (serosal or extraluminal compartment). The lumen was perfused with recirculating Krebs-Henseleit solution from a separate $20 \mathrm{~mL}$ bath (mucosal or intraluminal compartment) at constant flow $\left(12 \mathrm{~mL} \cdot \mathrm{min}^{-1}\right)$. Hydrostatic pressure was measured at the distal and proximal ends of the trachealis and the differential pressure $(\Delta \mathrm{P})$, which is a function of the airway diameter and reflects the resistance of the tracheal segment to perfusion, was recorded.

After equilibration, isoproterenol (Sigma) was added to assess basal tone. After washout, the trachea was extraluminally exposed to $40 \mathrm{mM} \mathrm{KCl}$ to obtain a receptor-independent reference response and washed again. Subsequently, a cumulative concentration-response curve was constructed with intraluminally administered methacholine. When used, the specific arginase inhibitor $N^{\omega}$-hydroxy-nor-L-arginine (norNOHA; $5.0 \mu \mathrm{M}$; kindly provided by J-L. Boucher, Université Paris V, Paris, France) and L-NAME (1.0 mM; Sigma) were applied to the intraluminal reservoir, while heparin (grade IA from porcine intestinal mucosa; 250 units $\cdot \mathrm{mL}^{-1}$; Sigma) was applied to both the intraluminal and extraluminal reservoirs; all $40 \mathrm{~min}$ prior to agonist-addition. L-Arginine $(5.0 \mathrm{mM}$; Sigma) was applied to the extraluminal reservoir $30 \mathrm{~min}$ prior to agonist addition.

\section{Bronchoalveolar lavage}

Animals were anaesthetised and the lungs were gently lavaged with saline via a tracheal cannula, using $5 \mathrm{~mL}$ of sterile saline at $37^{\circ} \mathrm{C}$, followed by three subsequent $8-\mathrm{mL}$ aliquots of saline. After centrifugation $\left(200 \times g, 10 \mathrm{~min}, 4^{\circ} \mathrm{C}\right)$, BAL cells were combined and resuspended in PBS, and total cell numbers were determined. For cytological examination, cytospin-preparations were stained with May-Grünwald and Giemsa (both Sigma) and a differential cell count was performed.

\section{Arginase assay}

Tracheal homogenates were prepared as described previously [27]. BAL cells were homogenised in $1.0 \mathrm{~mL} 20 \mathrm{mM}$ Tris- $\mathrm{HCl}$, $2 \mu \mathrm{M}$ phenylmethylsulphonyl fluoride (Sigma), $\mathrm{pH} 7.4$, using a polytron homogeniser (Kinematica $\mathrm{GmbH}$, Luzern, Switzerland). The homogenate was centrifuged $(20,000 \times g, 30 \mathrm{~min}$; $4{ }^{\circ} \mathrm{C}$ ) and the supernatant was used experimentally. Arginase activity was determined by measuring the conversion of L- 


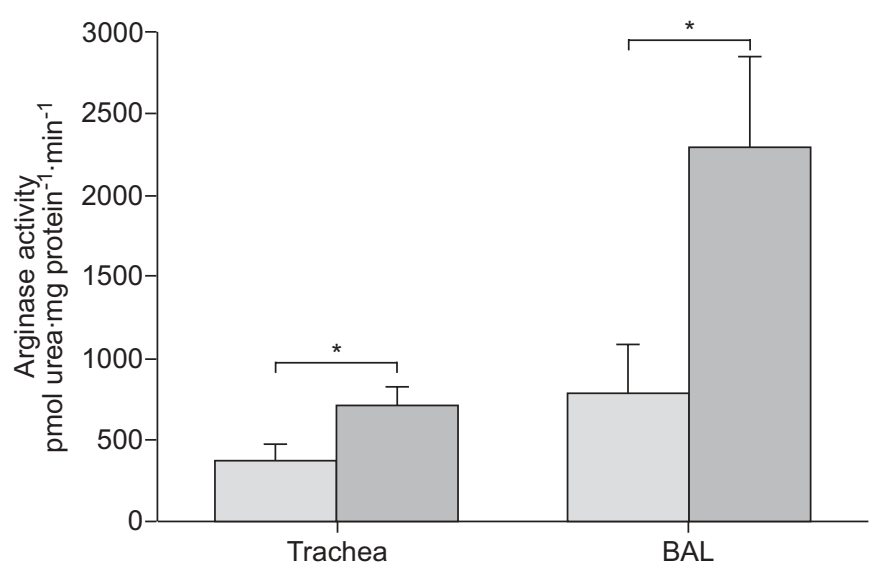

FIGURE 1. Arginase activity in tracheal and bronchoalveolar lavage (BAL) cell homogenates from unchallenged $(\square)$ and ovalbumin-challenged $(\square)$ guinea pigs. Data are presented as mean \pm SEM of $4-8$ experiments. *: $p<0.05$.

[guanido ${ }^{14} \mathrm{C}$ ]arginine (specific activity $51.5 \mathrm{mCi} \cdot \mathrm{mmol}^{-1}$; New England Nuclear Life Science Products, Boston, MA, USA) to $\left[{ }^{14} \mathrm{C}\right]$ urea, using a modified protocol as described by CusTOT et al. [29]. In short, homogenate aliquots $(50 \mu \mathrm{L})$ were incubated in a final volume of $150 \mu \mathrm{L}$, containing $25 \mathrm{mM}$ Tris-HCl, $0.67 \mathrm{mM} \mathrm{MnCl}{ }_{2}$ (Sigma), $1.66 \mathrm{mM}$ L-arginine and $1 \mu \mathrm{L}$ of L-[guanido- ${ }^{14} \mathrm{C}$ ]arginine $\left(51.5 \mathrm{mCi} \cdot \mathrm{mmol}^{-1}\right), \mathrm{pH} 7.4$, for $20 \mathrm{~min}$ at $37^{\circ} \mathrm{C}$. Reactions were terminated by adding $450 \mu \mathrm{L}$ of ice-cold stop buffer, containing $7 \mathrm{M}$ urea (Sigma), $0.25 \mathrm{M}$ acetic acid, $10 \mathrm{mM}$ L-arginine, $\mathrm{pH}$ 3.6. Samples were applied to vials containing $400 \mu \mathrm{L}$ Dowex AG 50W-X8 $\left(\mathrm{H}^{+}\right.$form, $1 \mathrm{~g} \cdot \mathrm{mL}^{-1}$; BioRad Laboratories, Hercules, CA, USA) and rotated for $2 \mathrm{~min}$. Vials were centrifuged at $750 \times g$ for $1 \mathrm{~min}$ and the resulting supernatants were centrifuged again for $1 \mathrm{~min}$. Final supernatants $(150 \mu \mathrm{L})$ were counted in triplicate in $4 \mathrm{~mL}$ Ultima Gold scintillation fluid (Packard Bioscience, Groningen, The Netherlands) using a Beckman LS 1701 liquid scintillation counter. The specificity of the assay in measuring arginase activity was confirmed by the inhibitory effect of nor-NOHA.

\section{Eosinophil peroxidase assay}

BAL cells were centrifuged and resuspended in Hanks' balanced salt solution to a final density of $2.5 \times 10^{6}$ cells $\cdot \mathrm{mL}^{-1}$ and incubated for $30 \mathrm{~min}$ at $37^{\circ} \mathrm{C}$. Cell incubation was stopped by placing the samples on ice, followed by immediate centrifugation and subsequent decantation of the supernatant for measurement of released EPO activity. Cells were lysed, centrifuged and the supernatant was collected to measure the remaining intracellular EPO content. EPO activity was analysed according to the kinetic assay described by WHITE et al. [30], which is based on the oxidation of O-phenylenediamine (Sigma) by $\mathrm{EPO}$ in the presence of hydrogen peroxide.

\section{Data analysis}

intraluminal responses of the tracheal tube preparations to methacholine were expressed as a percentage of the response induced by extraluminal administration of $40 \mathrm{mM} \mathrm{KCl}$. The contractile effect of $10 \mathrm{mM}$ methacholine (highest concentration) was defined as Emax. Using this Emax, the sensitivity to methacholine was evaluated as the -log half-maximal effective concentration (pEC50) value $[20,27,28]$.

Arginase activity was expressed as pmol urea produced per $\mathrm{mg}$ protein per min. EPO activity was expressed as a percentage of total amount of EPO (amount in supernatant of stimulated cells plus amount in supernatant of lysed cells).

Data are presented as mean \pm SEM. Statistical analysis was performed using an unpaired t-test, an ANOVA followed by a Bonferroni post hoc test, or a Kruskall-Wallis test followed by a Dunn's post hoc test, as appropriate. A p-value of 0.05 was considered statistically significant.

\section{RESULTS}

Arginase activity was significantly increased after the allergeninduced LAR, both in tracheal homogenates (1.9-fold; $\mathrm{p}<0.05$ ) and in homogenates of BAL cells (2.9-fold; $\mathrm{p}<0.05)$, compared with unchallenged controls (fig. 1). Total cell number, as well as the numbers of eosinophils and neutrophils in the BAL, was significantly increased $24 \mathrm{~h}$ after ovalbumin challenge (figs $2 \mathrm{a}$ and $2 b$ ). BAL eosinophils were activated after challenge, as
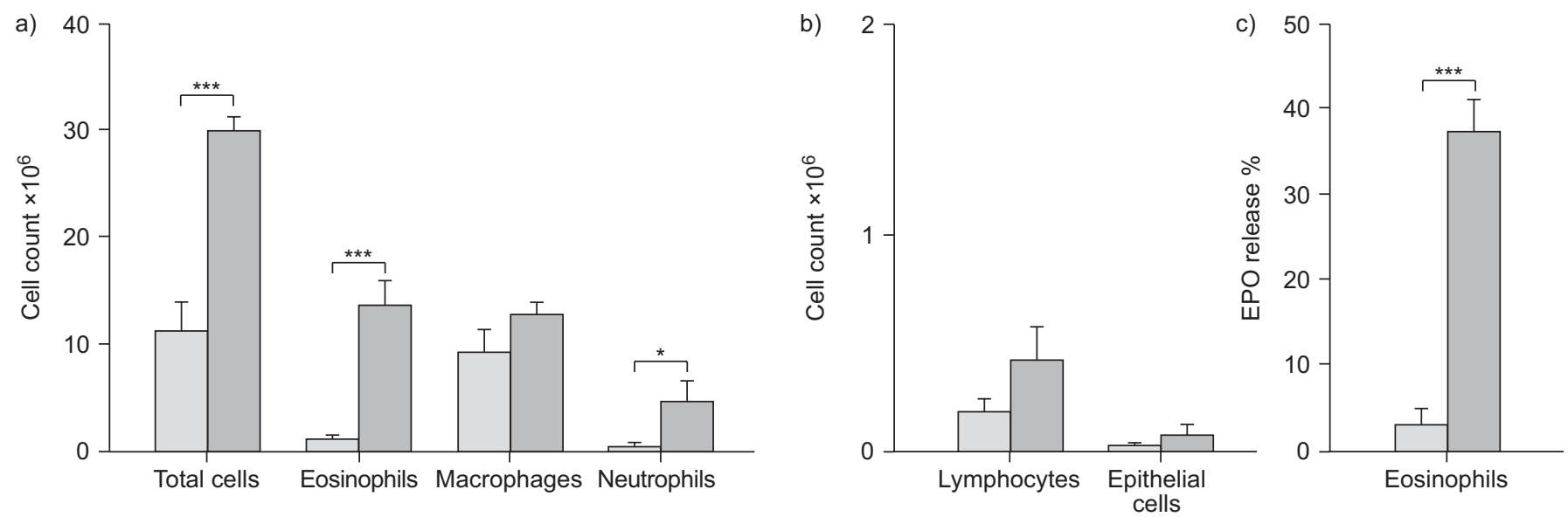

FIGURE 2. a, b) Total and differential cell count and c) eosinophil peroxidase (EPO) release from bronchoalveolar lavage eosinophils obtained from unchallenged ( $\square$ ) and ovalbumin-challenged $(\square)$ guinea pigs. EPO release is expressed as \% of total cellular EPO content and 100\% represents $19.3 \pm 3.9$ and $10.4 \pm 1.3 \mathrm{ng} \cdot \mathrm{mL}^{-1} \mathrm{EPO}$ per $10^{6}$ cells for unchallenged and ovalbumin challenged animals, respectively. Data are presented as mean \pm SEM of $4-8$ experiments. ${ }^{*}: p<0.05 ;{ }^{* * *}: p<0.001$ 


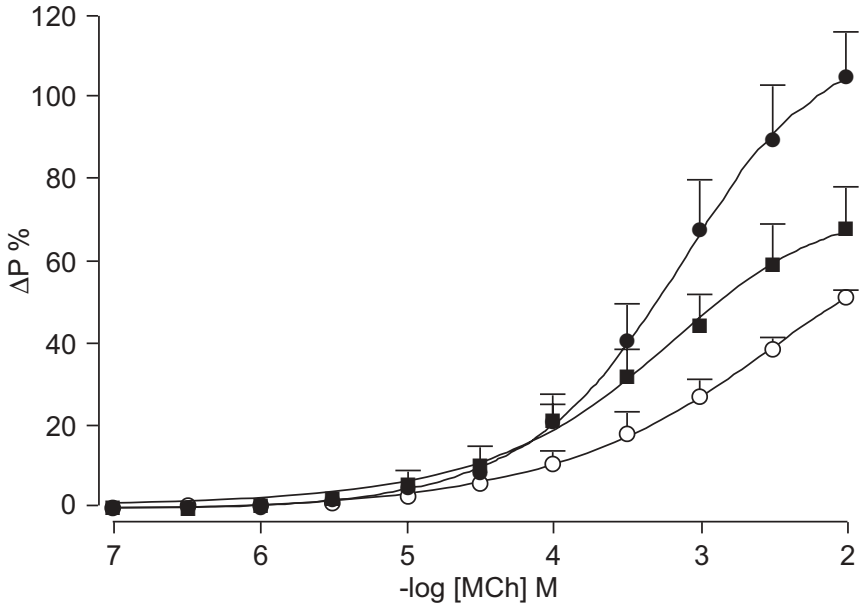

FIGURE 3. Methacholine (MCh)-induced constriction of intact perfused tracheae from unchallenged $(O)$ and ovalbumin-challenged $(\bullet)$ guinea pigs, presented as differential pressure $(\Delta \mathrm{P})$, in the absence and presence $(\boldsymbol{\square})$ of $5.0 \mathrm{mM}$ L-arginine. Data are presented as mean \pm SEM of 6-8 experiments.

indicated by increased spontaneous release of EPO by these cells (fig. 2c; $\mathrm{p}<0.001$ ).

Consistent with our previous study [11], a 2.0-fold increase in Emax to intraluminal methacholine was observed in perfused tracheal preparations obtained from ovalbumin-challenged guinea pigs after the LAR, compared with unchallenged controls $(\mathrm{p}<0.01)$, without a change in the sensitivity $(\mathrm{pEC} 50)$ to the agonist (fig. 3, table 1). Remarkably, the increase in Emax in these preparations was reduced by $70 \%$ after incubation with L-arginine $(5.0 \mathrm{~mm} ; \mathrm{p}<0.05)$, whereas the $\mathrm{pEC} 50$ value was unaffected (fig. 3, table 1).

Incubation of the preparations from ovalbumin-challenged animals with the arginase inhibitor nor-NOHA $(5.0 \mu \mathrm{M})$ completely reverted the AHR to methacholine to the level of unchallenged controls $(p<0.01)$, whereas no effect on the sensitivity was observed (fig. 4a, table 1). Similar to nor-NOHA,

\begin{tabular}{|c|c|c|c|c|}
\hline \multirow[t]{2}{*}{ TABLE 1} & \multicolumn{4}{|c|}{$\begin{array}{l}\text { Effects of nor-NOHA and heparin, in the absence } \\
\text { and presence of L-NAME, and L-arginine on the } \\
\text { responsiveness to intraluminally administered } \\
\text { methacholine of intact perfused tracheae from } \\
\text { ovalbumin-challenged guinea pigs }\end{array}$} \\
\hline & & Emax \% KCl & pEC50-log M & n \\
\hline \multicolumn{2}{|c|}{ Unchallenged } & $51.6 \pm 1.2$ & $3.12 \pm 0.20$ & 6 \\
\hline \multicolumn{2}{|c|}{ Ovalbumin challenged } & $105.1 \pm 10.8^{\star *}$ & $3.28 \pm 0.13$ & 8 \\
\hline \multicolumn{2}{|c|}{ + nor-NOHA $5.0 \mu \mathrm{M}$} & $52.8 \pm 5.2^{\# \#}$ & $3.41 \pm 0.15$ & 8 \\
\hline \multicolumn{2}{|c|}{ + nor-NOHA $5.0 \mu \mathrm{M}+\mathrm{L}-$} & $104.8 \pm 11.1^{\circ}$ & $3.48 \pm 0.16$ & 4 \\
\hline \multicolumn{5}{|c|}{ NAME $1.0 \mathrm{mM}$} \\
\hline \multicolumn{2}{|c|}{ + heparin $250 \mathrm{U} \cdot \mathrm{mL}^{-1}$} & $54.2 \pm 11.0^{\#}$ & $2.84 \pm 0.19$ & 6 \\
\hline \multicolumn{2}{|c|}{ + heparin $250 \mathrm{U} \cdot \mathrm{mL}^{-1}+\mathrm{L}-$} & $108.9 \pm 6.5^{+}$ & $3.25 \pm 0.08$ & 4 \\
\hline \multicolumn{5}{|c|}{ NAME $1.0 \mathrm{mM}$} \\
\hline \multicolumn{2}{|c|}{ + L-arginine $5.0 \mathrm{mM}$} & $67.6 \pm 11.0^{\#}$ & $3.16 \pm 0.15$ & 8 \\
\hline
\end{tabular}

Data are presented as mean \pm SEM. nor-NOHA: $N^{\omega}$-hydroxy-nor-l-arginine; L-NAME: $N^{\omega}$-nitro-L-arginine methyl ester; Emax: maximal effect obtained in the presence of $10 \mathrm{mM}$ methacholine; $\mathrm{pEC} 50$ : -log half-maximal effective concentration (sensitivity towards methacholine). ${ }^{* *} p<0.01$ compared with unchallenged control group; ${ }^{*}: p<0.05$; $\#: p<0.01$ compared with ovalbuminchallenged controls; and $\because: p<0.05$ compared with nor-NOHA; ${ }^{+}: p<0.05$ compared with heparin.

incubation with heparin $\left(250 \mathrm{U} \cdot \mathrm{mL}^{-1}\right)$ also normalised the airway responsiveness (fig. $4 \mathrm{~b}$, table $1 ; \mathrm{p}<0.05$ ). After co-incubation with L-NAME $(1.0 \mathrm{mM})$, the normalised responsiveness, both by norNOHA and by heparin, was completely reversed to the AHR of untreated ovalbumin-challenged airways (figs $4 \mathrm{a}$ and $4 \mathrm{~b}$, table 1 ; $\mathrm{p}<0.05$ for both). L-NAME, nor-NOHA, heparin and L-arginine had no effect on basal airway tone (not shown), which is in line with previous studies $[20,27,28]$.

\section{DISCUSSION}

The present study demonstrates for the first time that a deficiency, rather than an excess, of (presumably iNOS-derived)

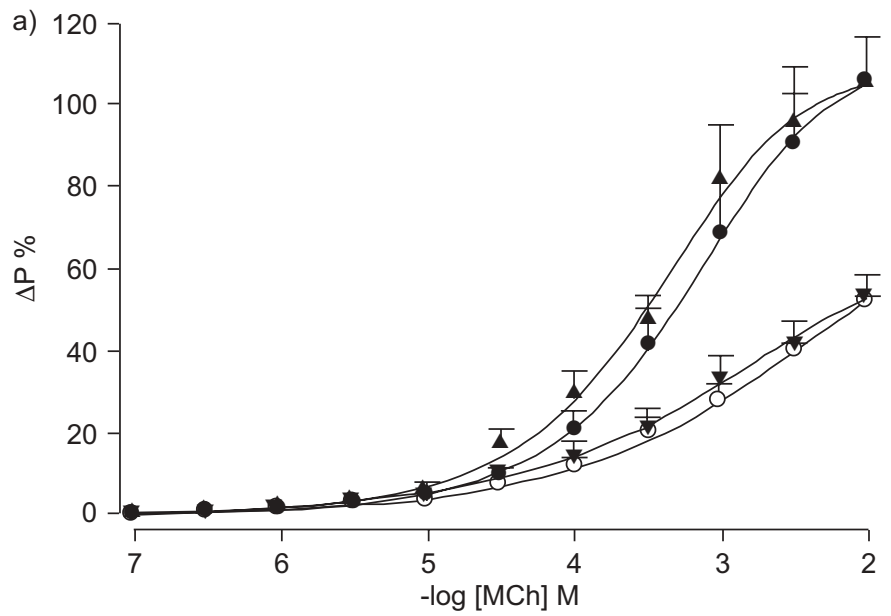

b)

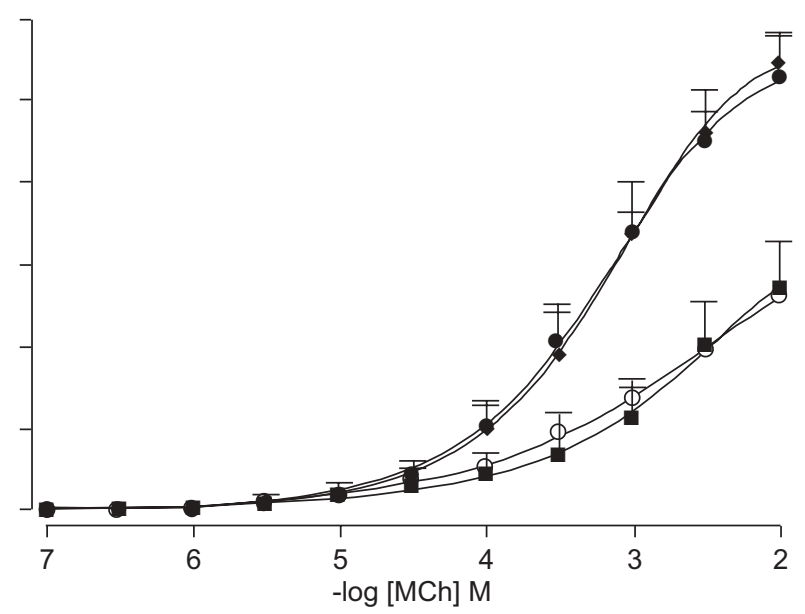

FIGURE 4. Methacholine (MCh)-induced constriction of intact perfused tracheae from unchallenged $(O)$ and ovalbumin-challenged $(\bullet)$ guinea pigs, presented as differential pressure $(\Delta \mathrm{P})$, compared with the addition of a) $5.0 \mu \mathrm{M} \mathrm{N} N^{\omega}$-hydroxy-nor-L-arginine (nor-NOHA) alone $(\mathbf{\nabla})$ or in combination with $1.0 \mathrm{mM} N^{\omega}$-nitro-L-arginine methyl ester (L-NAME) $(\mathbf{\Lambda})$ or b) $250 \mathrm{U} \cdot \mathrm{ml}^{-1}$ heparin alone $(\mathbf{\square})$ or in combination with $1.0 \mathrm{mM} \mathrm{L-NAME}$

$(\checkmark)$. Data are presented as mean \pm SEM of 4-9 experiments. 
$\mathrm{NO}$ is a prime cause of the development of AHR after the LAR. This NO deficiency is due to reduced bioavailability of Larginine in the airways, which may be caused by two distinct mechanisms: increased arginase activity, competing with iNOS for the common substrate; and enhanced release of eosinophilderived polycations, which inhibit L-arginine transport into the NO producing cells.

Using a guinea pig model of acute allergic asthma, we have previously demonstrated that both $\mathrm{NO}$, derived from iNOS which is induced during the $\operatorname{LAR}[4,10]$, and superoxide are involved the development of AHR after the LAR, presumably by the formation of peroxynitrite [11]. Thus, incubation of perfused tracheal preparations with L-NAME, as well as superoxide dismutase, fully reverted the AHR after the LAR in these preparations [11]. Remarkably, we have now demonstrated that L-arginine, as a precursor of NO, did not worsen but actually significantly decreased the AHR after the LAR. This may well be explained by the finding of XIA et al. [12] that, at low L-arginine concentrations, iNOS produces both NO by the oxygenase moiety of the enzyme and superoxide anion by its reductase moiety, leading to a highly efficient formation of peroxynitrite. Increasing the concentration of L-arginine promotes the production of $\mathrm{NO}$, while the generation of superoxide anion, and hence peroxynitrite, is reduced [12]. Therefore, allergen-induced limitation of L-arginine to iNOS caused by increased arginase activity and by polycations may be importantly involved in the development of AHR after the LAR, by promoting the generation of peroxynitrite. Notably, a role for arginase-induced L-arginine limitation in superoxide anion production by NOS has also been found in activated cultured cerebellar granule neurons [31]. Moreover, L-arginine limitation to iNOS has also been implicated in increased nitrotyrosine immunoreactivity associated with traumatic brain injury in rats [32].

Evidence is rising that most, if not all, of the deleterious effects induced by iNOS-derived NO in the airways may proceed via increased formation of peroxynitrite [8, 33, 34]. Generation of peroxynitrite has been indicated by enhanced nitrotyrosine immunostaining in the airways of allergen-challenged guinea pigs and of asthmatic patients [8, 35]. In asthmatic patients, increased nitrotyrosine staining was observed in the airway epithelium and inflammatory cells, which correlated with iNOS expression, AHR and airway inflammation [8]. In addition, iNOS expression and nitrotyrosine staining were closely colocalised in bronchial biopsies of these patients [8]. Interestingly, arginase I expression in asthmatic patients is particularly located to these same cells $[22,36]$. Furthermore, increased nitrotyrosine was found in exhaled breath condensate of asthmatic patients, which correlated with levels of exhaled NO [9]. Peroxynitrite has both procontractile and proinflammatory actions, which may contribute to the development of AHR [8, 11, 33-35, 37]. The procontractile action of peroxynitrite may involve oxidative inactivation of $\mathrm{K}_{\mathrm{Ca}}$ channels and sarco/endoplasmatic reticulum $\mathrm{Ca}^{2+}$-ATPase type-2 [11, 38-41]. In addition, peroxynitrite has been shown to induce degranulation of eosinophils, epithelial damage and AHR [33, 34], as well as airway microvascular hyperpermeability [35] in guinea pigs. Collectively, the data indicate that not iNOS-derived NO itself, but rather its reaction with (iNOSderived) superoxide anions to peroxynitrite importantly accounts for the detrimental effects of increased iNOS expression after the LAR. Moreover, increased scavenging of NO by superoxide anion to form peroxynitrite also contributes to the AHR by causing a deficiency of authentic, bronchodilating $\mathrm{NO}$.

That iNOS-derived NO may have beneficial effects on airway responsiveness was nicely demonstrated by a study of HJOBERG et al. [42], using iNOS overexpressing mice. As in asthmatics, levels of exhaled $\mathrm{NO}$ are increased in these mice compared with wild type. Interestingly, iNOS-derived NO per se had no proinflammatory effects in the airways and even decreased airway responsiveness to methacholine [42]. Using in vivo studies in our guinea pig model of allergic asthma, we have previously demonstrated that iNOS-derived NO, aside from promoting airway inflammation and epithelial damage, also had some beneficial effect on allergen-induced AHR after the LAR, by partially attenuating the hyperresponsiveness due to its bronchodilating effect [10]. Remarkably, treatment with a selective iNOS inhibitor did not affect allergen-induced AHR in asthmatic patients, although levels of exhaled NO were markedly reduced [43].

One mechanism underlying L-arginine limitation after the LAR is increased arginase activity in the airways, which was found in tracheal homogenates as well as in BAL cells, indicating that inflammatory cells may be involved. The AHR after the LAR was completely normalised by the arginase inhibitor norNOHA, demonstrating a prominent role for arginase in the development of L-arginine limitation and AHR. Co-incubation with L-NAME completely restored the AHR, indicating that arginase inhibition restores bronchodilating NO production. Using guinea pig tracheal preparations, we have previously demonstrated that arginase activity in the airways is already increased after the early asthmatic reaction and contributes to AHR after this reaction by causing a marked deficiency of both neural and agonist-induced non-neural NO, by limiting the availability of L-arginine to cNOS [27, 44]. Thus, L-arginine limitation, due to increased arginase activity is importantly involved in the development of AHR both after the early and late asthmatic reaction. Very recently, these ex vivo observations were confirmed by in vivo studies using the same guinea pig model [45]. Inhalation of the specific arginase inhibitor, 2(S)-amino-6-boronohexanoic acid ( $\mathrm{ABH})$, acutely reversed the allergen-induced AHR after the EAR and LAR, while pretreatment with $\mathrm{ABH}$ protected against the development of the AHR after both reactions. Quite remarkably, $\mathrm{ABH}$ also reduced the airway sensitivity to the inhaled allergen and protected against the allergen-induced bronchial obstructive reactions and airway inflammation [45]. Accordingly, intraperitoneal treatment with nor-NOHA significantly decreased allergeninduced AHR as well as inflammatory cell infiltration in the lungs of C57BL/6 mice, following 2 weeks of ovalbumin challenge [46]. In contrast, oropharyngeal aspiration of the arginase inhibitor, S-(2-boronoethyl)-L-cysteine (BEC), $2 \mathrm{~h}$ after the last of three daily ovalbumin challenges did not affect allergen-induced inflammatory cell profiles or levels of 21 cytokines in the BAL fluid of BALB/c mice, with the exception of interleukin (IL)-4, which was reduced [47]. However, allergen-induced peribronchiolar and perivascular inflammation and protein nitration were further enhanced by BEC treatment [47]. Remarkably, although the allergen-induced 
Cytokines

$($ IFN-Y, TNF- $\alpha$, IL-1 $\beta$ )
Cytokines

(IL-4, IL-13)
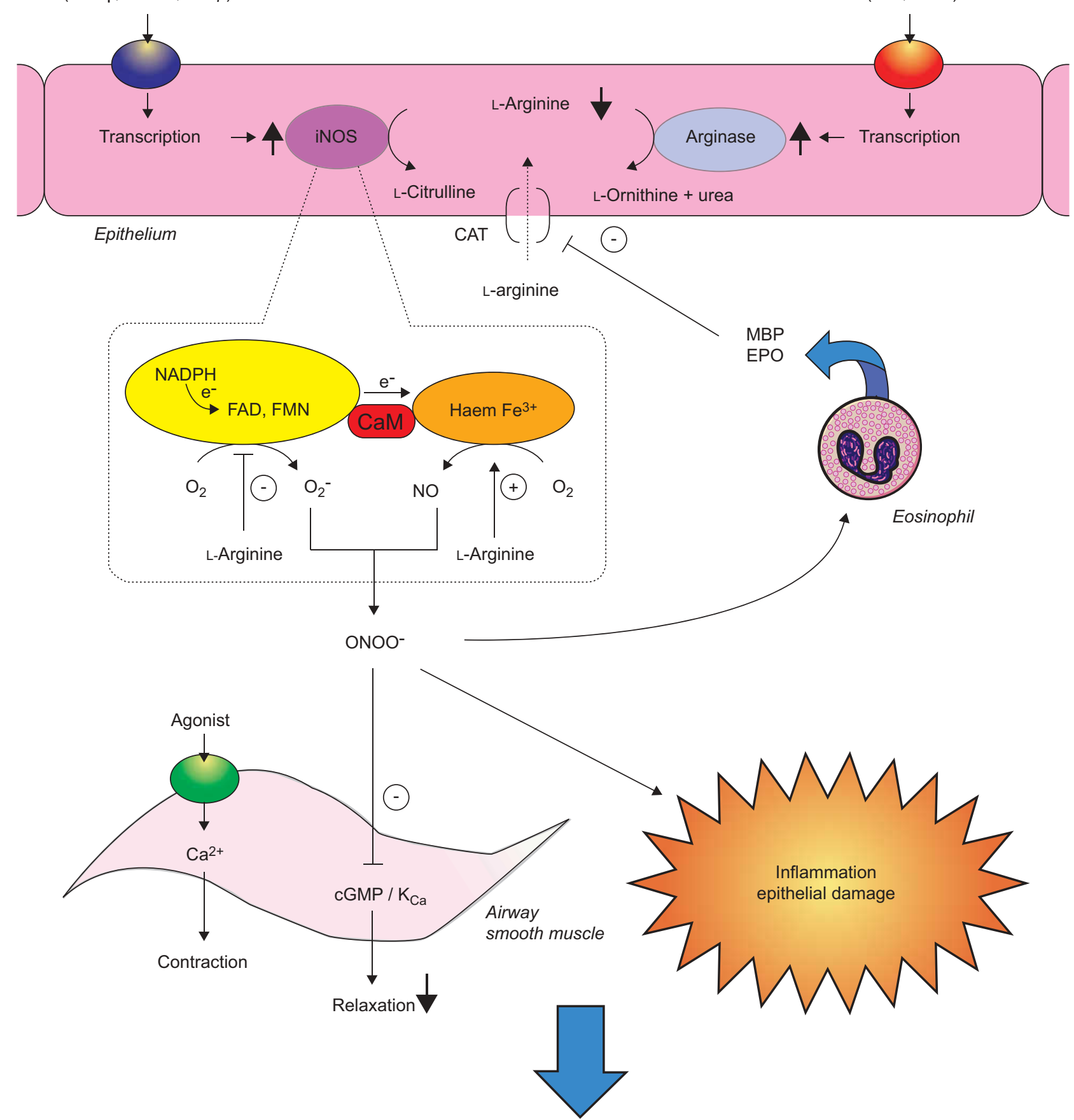

Airway hyperresponsiveness

FIGURE 5. Postulated role of L-arginine homeostasis in the development of airway hyperresponsiveness (AHR) after the late asthmatic reaction (LAR). Increased arginase activity, which may be induced by Th2 cytokines in the airway epithelium and in inflammatory cells (not shown), as well as increased release of eosinophil-derived polycations result in a decreased availability of L-arginine to inducible nitric oxide synthase (iNOS), which is induced in the same cells during the LAR. The reduced availability of $\mathrm{L}$-arginine to iNOS promotes the production of superoxide anion $\left(\mathrm{O}_{2}^{-}\right)$by the reductase moiety of the enzyme. NO, produced by the oxygenase moiety, and $\mathrm{O}_{2}^{-}$rapidly react to form the highly reactive nitrogen species peroxynitrite ( $\left.\mathrm{ONOO}^{-}\right)$, which has procontractile and proinflammatory actions in the airways and contributes to the allergeninduced AHR. Moreover, the formation of ONOO- causes a relative deficiency of bronchodilating NO, similarly contributing to the AHR. Increasing the L-arginine availability, by inhibition of arginase activity or restoring cellular transport of the amino acid, diminishes the AHR by inhibiting $\mathrm{O}_{2}^{-}$production and stimulating the production of authentic, bronchodilating NO. CaM: calmodulin; CAT: cationic amino acid transporter; EPO: eosinophil peroxidase, FAD: flavin adenine dinucleotide, FMN: flavin mononucleotide, IFN: interferon, IL; interleukin, $\mathrm{K}_{\mathrm{Ca}}$ : $\mathrm{Ca}^{2+}$-dependent potassium channel, MBP: major basic protein, NADPH: reduced nicotinamide adenine dinucleotide phosphate, TNF: tumour necrosis factor. 
increase in peripheral airway responsiveness at $40 \mathrm{~s}$ after methacholine inhalation appeared to be reduced, the peakresponse to methacholine was not inhibited but rather accelerated by BEC [47]. Furthermore, no effect of BEC on allergen-induced hyperresponsiveness of the central airways was observed [47]. An explanation for these unexpected observations is presently not yet at hand. However, a recent study of acetylcholine-induced vasorelaxation suggested that BEC may also have other cellular targets than arginase [48].

The importance of increased arginase expression and activity in allergic asthma has been confirmed in different animal models as well as in asthmatic patients [49]. Thus, in two mouse models of allergic asthma, induced by sensitisation with ovalbumin and Aspergillus fumigatus, respectively, pulmonary arginase activity was increased after allergen challenge [22]. Microarray analysis of gene expression in these models revealed that genes related to L-arginine metabolism, including the cytosolic isoform arginase I and the mitochondrial isoform arginase II, belonged to the most prominently overexpressed genes [22]. Increased arginase expression and activity in mouse lung has also been found in other studies, after challenge with either ovalbumin [50-52], Nippostrongylus brasiliensis [52], Schistosoma mansoni eggs [53], Dermatophagoides farinae [54] or trimellic anhydride [51]. In addition, ovalbumin increased arginase activity in the lungs of sensitised rats [55]. Moreover, mouse lung arginase activity and mRNA expression of both arginase I and II were strongly induced by the T-helper cell type 2 cytokines IL-4 and IL-13, known to be involved in allergic airway inflammation $[22,52,56]$. Similar observations were made in cultured rat airway fibroblasts [21].

In support of our findings, protein expression of arginase I was increased in BAL cells (presumably alveolar macrophages) of asthmatic patients [22]. In addition, enhanced mRNA expression of arginase I was observed in the airway epithelium and in inflammatory cells in bronchial biopsies of these patients [22], strongly indicating that arginase is involved in the pathophysiology of human asthma. Interestingly, increased serum arginase activity and decreased plasma levels of Larginine have been observed in asthmatic patients during exacerbation [57]. Moreover, in another study serum arginase activity in severe asthmatics was inversely correlated to forced expiratory volume in $1 \mathrm{~s}$ (FEV1) and FEV1/forced vital capacity, whereas lung function was positively correlated to plasma L-arginine availability in these patients [58]. Since immunohistological detection of guinea pig arginase is presently not yet possible, the cellular localisation of the allergen-induced increased arginase expression in these animals remains to be established.

A second important mechanism regulating cellular L-arginine availability to NOS is the uptake of the amino acid by CATs. Using the polyanion heparin, acting as a polycation antagonist, we previously demonstrated that endogenous polycations contribute to the NO deficiency and AHR after the early asthmatic reaction, presumably by inhibiting cellular Larginine uptake [28]. Indeed, eosinophil-derived polycations as well as poly-L-arginine are known to inhibit L-arginine uptake [17] and to cause AHR by affecting airway epithelial function [59] and inducing NO deficiency [18]. Interestingly, we have now demonstrated that heparin completely normalised
AHR after the LAR, indicating that endogenous polycations are involved in this process as well. Since the effect of heparin was reversed by L-NAME, it can be concluded that heparin normalises the AHR by restoring the production of bronchodilating NO. The similar effects of arginase inhibition and polycation scavenging on AHR suggest a common pathophysiological pathway, which could implicate an increased effectiveness of arginase under conditions of polycation-induced substrate limitation.

In line with our hypothesis that eosinophil-derived polycations are involved in the development of AHR, we demonstrated that both the number and activation state of eosinophils in the BAL were markedly increased after allergen challenge. The increased EPO release by the BAL cells found in the present study corresponds to our previous finding of increased EPO activity in the BAL fluid $24 \mathrm{~h}$ after ovalbumin challenge, which correlated with AHR in vivo [60]. Previous studies have indicated that treatment with inhaled heparin before allergen challenge significantly reduced allergen-induced pulmonary eosinophilia in sensitised guinea pigs [61]. In addition, in asthmatic patients and in allergen-challenged sheep and guinea pigs, (pretreatment with) inhaled heparin was found to inhibit AHR to various contractile agonists [62-66]. Similar to the arginase inhibitor $\mathrm{ABH}$ [45], pretreatment with inhaled heparin also reduced allergen-induced bronchial obstructive reactions in allergic sheep and guinea pigs [64, 66, 67]. Furthermore, both exercise- and allergen-induced asthmatic reactions in asthmatic patients were reduced by inhaled heparin as well [68-70]. However, inhalation of the heparinderivative IVX-0142 did not significantly affect allergeninduced early and late asthmatic responses, AHR and exhaled NO in patients with mild asthma, which may have been due to underdosing of the drug [71].

In conclusion, using a well defined guinea pig model of allergic asthma, we have demonstrated that a deficiency of bronchodilating NO in the airway wall, due to arginase- and polycation-induced attenuation of L-arginine availability, is involved in the development of AHR after the LAR. This process may involve simultaneous production of $\mathrm{NO}$ and superoxide anion by iNOS at a low L-arginine concentration, leading to very efficient formation of the proinflammatory and procontractile nitrogen species peroxynitrite as well as reduced levels of bronchodilating NO (fig. 5). Since the AHR is reduced by both nor-NOHA and heparin, arginase inhibitors and polycation antagonists may have therapeutic potential in allergic asthma.

\section{SUPPORT STATEMENT}

This study was financially supported by the Netherlands Asthma Foundation (grant 00.24).

\section{STATEMENT OF INTEREST}

None declared.

\section{ACKNOWLEDGEMENTS}

The authors wish to thank J. De Boer (University of Groningen, Groningen, The Netherlands) for technical support and J-L. Boucher (Université Paris Descartes, Paris, France) for providing nor-NOHA. 


\section{REFERENCES}

1 Cartier A, Thomson NC, Frith PA, et al. Allergen-induced increase in bronchial responsiveness to histamine: relationship to the late asthmatic response and change in airway caliber. J Allergy Clin Immunol 1982; 70: 170-177.

2 Santing RE, Olymulder CG, Zaagsma J, et al. Relationships among allergen-induced early and late phase airway obstructions, bronchial hyperreactivity, and inflammation in conscious, unrestrained guinea pigs. J Allergy Clin Immunol 1994; 93: 1021-1030.

3 Kharitonov S, O'connor BJ, Evans DJ, et al. Allergen-induced late asthmatic reactions are associated with elevation of exhaled nitric oxide. Am J Respir Crit Care Med 1995; 151: 1894-1897.

4 Yan ZQ, Hanson GK, Skoogh BE, et al. Induction of nitric oxide synthase in a model of allergic occupational asthma. Allergy 1995; 50: 760-764.

5 Dupont LJ, Rochette F, Demedts MG, et al. Exhaled nitric oxide correlates with airway hyperresponsiveness in steroid-naive patients with mild asthma. Am J Respir Crit Care Med 1998; 157: 894-898.

6 Jatakanon A, Lim S, Kharitonov SA, et al. Correlation between exhaled nitric oxide, sputum eosinophils, and methacholine responsiveness in patients with mild asthma. Thorax 1998; 53: 91-95.

7 Kharitonov S, Yates DH, Barnes PJ. Inhaled glucocorticoids decrease nitric oxide in exhaled air of asthmatic patients. Am J Respir Crit Care Med 1996; 153: 454-457.

8 Saleh D, Ernst P, Lim S, et al. Increased formation of the potent oxidant peroxynitrite in the airways of asthmatic patients is associated with induction of nitric oxide synthase: effect of inhaled glucocorticoid. FASEB J 1998; 12: 929-937.

9 Hanazawa T, Kharitonov SA, Barnes PJ. Increased nitrotyrosine in exhaled breath condensate of patients with asthma. Am J Respir Crit Care Med 2000; 162: 1273-1276.

10 Schuiling M, Meurs H, Zuidhof AB, et al. Dual action of iNOSderived nitric oxide in allergen-induced airway hyperreactivity in conscious, unrestrained guinea pigs. Am J Respir Crit Care Med 1998; 158: 1442-1449.

11 de Boer J, Meurs H, Flendrig L, et al. Role of nitric oxide and superoxide in allergen-induced airway hyperreactivity after the late asthmatic reaction in guinea-pigs. Br J Pharmacol 2001; 133: 1235-1242.

12 Xia Y, Roman LJ, Masters BS, et al. Inducible nitric-oxide synthase generates superoxide from the reductase domain. J Biol Chem 1998; 273: 22635-22639.

13 Ricciardolo FL, Sterk PJ, Gaston B, et al. Nitric oxide in health and disease of the respiratory system. Physiol Rev 2004; 84: 731-765.

14 Meurs H, Maarsingh H, Zaagsma J. Arginase and asthma: novel insights into nitric oxide homeostasis and airway hyperresponsiveness. Trends Pharmacol Sci 2003; 24: 450-455.

15 Ricciardolo FL, Zaagsma J, Meurs H. The therapeutic potential of drugs targeting the arginase pathway in asthma. Expert Opin Investig Drugs 2005; 14: 1221-1231.

16 Closs EI, Simon A, Vekony N, et al. Plasma membrane transporters for arginine. J Nutr 2004; 134: 2752S-2759S.

17 Hammermann R, Hirschmann J, Hey C, et al. Cationic proteins inhibit L-arginine uptake in rat alveolar macrophages and tracheal epithelial cells. Implications for nitric oxide synthesis. Am J Respir Cell Mol Biol 1999; 21: 155-162.

18 Meurs H, Schuurman FE, Duyvendak M, et al. Deficiency of nitric oxide in polycation-induced airway hyperreactivity. $\mathrm{Br} J$ Pharmacol 1999; 126: 559-562.

19 Que LG, Kantrow SP, Jenkinson CP, et al. Induction of arginase isoforms in the lung during hyperoxia. Am J Physiol 1998; 275: L96-L102.

20 Meurs H, Hamer MA, Pethe S, et al. Modulation of cholinergic airway reactivity and nitric oxide production by endogenous arginase activity. Br J Pharmacol 2000; 130: 1793-1798.
21 Lindemann D, Racke K. Glucocorticoid inhibition of interleukin-4 (IL-4) and interleukin-13 (IL-13) induced up-regulation of arginase in rat airway fibroblasts. Naunyn Schmiedebergs Arch Pharmacol 2003; 368: 546-550.

22 Zimmermann N, King NE, Laporte J, et al. Dissection of experimental asthma with DNA microarray analysis identifies arginase in asthma pathogenesis. J Clin Invest 2003; 111: 1863-1874.

23 Maarsingh H, Tio MA, Zaagsma J, et al. Arginase attenuates inhibitory nonadrenergic noncholinergic nerve-induced nitric oxide generation and airway smooth muscle relaxation. Respir Res 2005; 6: 23.

24 Maarsingh H, Zaagsma J, Meurs H. Arginine homeostasis in allergic asthma. Eur J Pharmacol 2008; 585: 375-384.

25 Van Amsterdam RG, Brouwer F, Zaagsma J. Analysis of the $\beta$ adrenoceptor mediated inhibition of IgG1 and IgE dependent guinea-pig anaphylactic tracheal smooth muscle contraction. Agents Actions 1989; 26: 48-51.

26 Meurs H, Santing RE, Remie R, et al. A guinea pig model of acute and chronic asthma using permanently instrumented and unrestrained animals. Nat Protoc 2006; 1: 840-847.

27 Meurs H, McKay S, Maarsingh H, et al. Increased arginase activity underlies allergen-induced deficiency of cNOS-derived nitric oxide and airway hyperresponsiveness. Br J Pharmacol 2002; 136 391-398.

28 Maarsingh $\mathrm{H}$, de Boer J, Kauffman HF, et al. Heparin normalizes allergen-induced nitric oxide deficiency and airway hyperresponsiveness. Br J Pharmacol 2004; 142: 1293-1299.

29 Custot J, Boucher J-L, Vadon S, et al. N- $\omega$-hydroxy-alpha-amino acids as a new class of very strong inhibitors of arginases. $J$ Biol Inorg Chem 1996; 1: 73-82.

30 White SR, Kulp GV, Spaethe SM, et al. A kinetic assay for eosinophil peroxidase activity in eosinophils and eosinophil conditioned media. J Immunol Methods 1991; 144: 257-263.

31 Culcasi M, Lafoncazal M, Pietri S, et al. Glutamate receptors induce a burst of superoxide via activation of nitric-oxide synthase in arginine-depleted neurons. J Biol Chem 1994; 269: 12589-12593.

32 Avila MA, Sell SL, Kadoi Y, et al., L-Arginine decreases fluidpercussion injury-induced neuronal nitrotyrosine immunoreactivity in rats. J Cereb Blood Flow Metab 2008; 28: 1733-1741.

33 Sadeghi-Hashjin G, Folkerts G, Henricks PAJ, et al. Peroxynitrite in airway diseases. Clin Exp Allergy 1998; 28: 1464-1473.

34 Sadeghi-Hashjin G, Folkerts G, Henricks PAJ, et al. Peroxynitrite induces airway hyperresponsiveness in guinea pigs in vitro and in vivo. Am J Respir Crit Care Med 1996; 153: 1697-1701.

35 Sugiura H, Ichinose M, Oyake T, et al. Role of peroxynitrite in airway microvascular hyperpermeability during late allergic phase in guinea pigs. Am J Respir Crit Care Med 1999; 160: 663-671.

36 Bergeron C, Boulet LP, Page N, et al. Influence of cigarette smoke on the arginine pathway in asthmatic airways: increased expression of arginase I. J Allergy Clin Immunol 2007; 119: 391-397.

37 Muijsers RB, Van der Veeken A, Habernickel J, et al. Intra-luminal exposure of murine airways to peroxynitrite causes inflammation but not hyperresponsiveness. Inflamm Res 2002; 51: 33-37.

38 Elliott SJ, Lacey DJ, Chilian WM, et al. Peroxynitrite is a contractile agonist of cerebral artery smooth muscle cells. Am J Physiol 1998; 275: H1585-H1591.

39 Brzezinska AK, Gebremedhin D, Chilian WM, et al. Peroxynitrite reversibly inhibits $\mathrm{Ca}(2+)$-activated $\mathrm{K}(+)$ channels in rat cerebral artery smooth muscle cells. Am J Physiol Heart Circ Physiol 2000; 278: H1883-H1890.

40 Viner RI, Ferrington DA, Huhmer AF, et al. Accumulation of nitrotyrosine on the SERCA2a isoform of SR Ca-ATPase of rat skeletal muscle during aging: a peroxynitrite-mediated process? FEBS Lett 1996; 379: 286-290.

41 Viner RI, Huhmer AF, Bigelow DJ, et al. The oxidative inactivation of sarcoplasmic reticulum $\mathrm{Ca}(2+)$-ATPase by peroxynitrite. Free Radic Res 1996; 24: 243-259. 
42 Hjoberg J, Shore S, Kobzik L, et al. Expression of nitric oxide synthase- 2 in the lungs decreases airway resistance and responsiveness. J Appl Physiol 2004; 97: 249-259.

43 Singh D, Richards D, Knowles RG, et al. Selective inducible nitric oxide synthase inhibition has no effect on allergen challenge in asthma. Am J Respir Crit Care Med 2007; 176: 988-993.

44 Maarsingh $\mathrm{H}$, Leusink J, Bos IST, et al. Arginase strongly impairs neuronal nitric oxide-mediated airway smooth muscle relaxation in allergic asthma. Respir Res 2006; 7: 6.

45 Maarsingh $\mathrm{H}$, Zuidhof $\mathrm{AB}$, Bos IS, et al. Arginase inhibition protects against allergic airway obstruction, hyperresponsiveness and inflammation. Am J Respir Crit Care Med 2008; 178: 565-573.

46 Bratt JM, Franzi LM, Linderholm AL, et al. Arginase enzymes in isolated airways from normal and nitric oxide synthase 2-knockout mice exposed to ovalbumin. Toxicol Appl Pharmacol 2009; 234: 273-280.

47 Ckless K, Lampert A, Reiss J, et al. Inhibition of arginase activity enhances inflammation in mice with allergic airway disease, in association with increases in protein S-nitrosylation and tyrosine nitration. J Immunol 2008; 181: 4255-4264.

48 Huynh N, Harris E, Chin-Dusting J, et al. The vascular effects of different arginase inhibitors in rat isolated aorta and mesenteric arteries. Br J Pharmacol 2009; 156: 84-93.

49 Maarsingh H, Pera T, Meurs H. Arginase and pulmonary diseases. Naunyn Schmiedebergs Arch Pharmacol 2008; 378: 171-184.

50 Fajardo I, Svensson L, Bucht A, et al. Increased levels of hypoxiasensitive proteins in allergic airway inflammation. Am J Respir Crit Care Med 2004; 170: 477-484.

51 Greene AL, Rutherford MS, Regal RR, et al. Arginase activity differs with allergen in the effector phase of ovalbumin- versus trimellitic anhydride-induced asthma. Toxicol Sci 2005; 88: 420-433.

52 Lewis CC, Yang JY, Huang X, et al. Disease-specific gene expression profiling in multiple models of lung disease. Am J Respir Crit Care Med 2007; 177: 376-387.

53 Sandler NG, Mentink-Kane MM, Cheever AW, et al. Global gene expression profiles during acute pathogen-induced pulmonary inflammation reveal divergent roles for Th1 and Th2 responses in tissue repair. J Immunol 2003; 171: 3655-3667.

54 Takemoto K, Shibamori M, Hitomi Y, et al. Transiently, paralleled upregulation of arginase and nitric oxide synthase and the effect of both enzymes on the pathology of asthma. Am J Physiol Lung Cell Mol Physiol 2007; 293: L1419-L1426.

55 Abe M, Hayashi Y, Murai A, et al. Effects of inducible nitric oxide synthase inhibitors on asthma depending on administration schedule. Free Radic Biol Med 2006; 40: 1083-1095.

56 Yang M, Rangasamy D, Matthaei KI, et al. Inhibition of arginase I activity by RNA interference attenuates IL-13-induced airways hyperresponsiveness. J Immunol 2006; 177: 5595-5603.
57 Morris CR, Poljakovic M, Lavrisha L, et al. Decreased arginine bioavailability and increased serum arginase activity in asthma. Am J Respir Crit Care Med 2004; 170: 148-153.

58 Lara A, Khatri SB, Wang Z, et al. Alterations of the arginine metabolome in asthma. Am J Respir Crit Care Med 2008; 178: 673-681.

59 Homma T, Bates JH, Irvin CG. Airway hyperresponsiveness induced by cationic proteins in vivo: site of action. Am J Physiol Lung Cell Mol Physiol 2005; 289: L413-L418.

60 Santing RE, Hoekstra Y, Pasman Y, et al. The importance of eosinophil activation for the development of allergen- induced bronchial hyperreactivity in conscious, unrestrained guinea- pigs. Clin Exp Allergy 1994; 24: 1157-1163.

61 Seeds EA, Page CP. Heparin inhibits allergen-induced eosinophil infiltration into guinea-pig lung via a mechanism unrelated to its anticoagulant activity. Pulm Pharmacol Ther 2001; 14: 111-119.

62 Ceyhan B, Celikel T. Effect of inhaled heparin on methacholineinduced bronchial hyperreactivity. Chest 1995; 107: 1009-1012.

63 Ceyhan BB, Celikel T. Effect of inhaled low molecular weight heparin on methacholine-induced bronchoconstriction. Int J Clin Pharmacol Ther 2000; 38: 446-451.

64 Ahmed T, Syriste T, Mendelssohn R, et al. Heparin prevents antigen-induced airway hyperresponsiveness: interference with IP3-mediated mast cell degranulation? J Appl Physiol 1994; 76: 893-901.

65 Molinari JF, Campo C, Shakir S, et al. Inhibition of antigen-induced airway hyperresponsiveness by ultralow molecular-weight heparin. Am J Respir Crit Care Med 1998; 157: 887-893.

66 Yahata T, Nishimura Y, Maeda H, et al. Modulation of airway responsiveness by anionic and cationic polyelectrolyte substances. Eur J Pharmacol 2002; 434: 71-79.

67 Ahmed T, Ungo J, Zhou M, et al. Inhibition of allergic late airway responses by inhaled heparin-derived oligosaccharides. J Appl Physiol 2000; 88: 1721-1729.

68 Ahmed T, Garrigo J, Danta I. Preventing bronchoconstriction in exercise-induced asthma with inhaled heparin. N Engl J Med 1993; 329: 90-95.

69 Bowler SD, Smith SM, Lavercombe PS. Heparin inhibits the immediate response to antigen in the skin and lungs of allergic subjects. Am Rev Respir Dis 1993; 147: 160-163.

70 Diamant Z, Timmers MC, Van D, et al. Effect of inhaled heparin on allergen-induced early and late asthmatic responses in patients with atopic asthma. Am J Respir Crit Care Med 1996; 153: 1790-1795.

71 Duong M, Cockcroft D, Boulet LP, et al. The effect of IVX-0142, a heparin-derived hypersulfated disaccharide, on the allergic airway responses in asthma. Allergy 2008; 63: 1195-1201. 